\title{
A Organização das Nações Unidas e seu Papel na Manutenção da Paz: Uma Análise Sobre suas Potencialidades Políticas
}

\begin{abstract}
Gilmar Antonio Bedin
Doutor em Direito pela Universidade Federal de Santa Catarina - UFSC. Pós-doutorando pela Universidade de Santiago do Chile USACH. Professor permanente do Programa de Pós-Graduação Stricto Sensu em Direito - Mestrado e Doutorado em Direitos Humanos da Universidade Regional do Noroeste do Estado do Rio Grande do Sul - Unijuí e do Programa de Pós-Graduação Stricto Sensu em Direito - Mestrado e Doutorado da Universidade Regional Integrada do Alto Uruguai e das Missões - URI. Líder do Grupo de Pesquisa do CNPq: Direitos Humanos, Governança e Democracia. http://lattes.cnpq.br/0553982956028307. https://orcid.org/00000001-9183-7065. gilmarb@unijui.edu.br
\end{abstract}

\section{Aline Michele Pedron Leves}

Mestra pelo Programa de Pós-Graduação Stricto Sensu em Direito - Curso de Mestrado em Direitos Humanos da Universidade Regional do Noroeste do Estado do Rio Grande do Sul - Unijuí. Bacharela em Direito pela Unijuí. Integrante do Grupo de Pesquisa do CNPq: Direitos Humanos, Governança e Democracia. Advogada. http://lattes.cnpq.br/9564252232431565. https://orcid.org/00000002-0371-5234. alineleves@hotmail.com

O retorno à história da civilização demonstra que esta sempre foi permeada por inúmeros conflitos, paradoxos e incoerências, como também por conquistas e significativos progressos. Isso significa que a sociedade internacional foi palco de profundas transformações que a tornaram mais complexa e menos centrada na figura dos Estados soberanos. Notadamente, a partir da Segunda Guerra Mundial, a manutenção da paz e da segurança internacional emergiram como necessidades vitais. Assim sendo, com o fenômeno da globalização e o surgimento de novos atores internacionais, verificou-se o deslocamento do velho sistema anárquico westfaliano para um conjunto internacional de arranjos bifurcados, assentado em uma sociedade multicêntrica e interdependente. Daí, portanto, o presente artigo objetiva analisar, por meio do método hipotético-dedutivo e da técnica de pesquisa bibliográfica, o papel desempenhado pela ONU no que diz respeito a sua missão fundamental para o estabelecimento de uma comunidade de paz.

Palavras-chave: Organização das Nações Unidas. Soberania estatal. Conflitos internacionais. Paz. Direitos humanos.

THE UNITED NATIONS ORGANIZATION AND ITS ROLE IN MAINTENANCE OF PEACE: AN ANALYSIS ABOUT ITS POLITICAL POTENTIALITIES

\section{ABSTRACT}

The return to the history of civilization shows that it has always been permeated by numerous conflicts, paradoxes and inconsistencies, as well as by achievements and significant progress. This means that international society was undergone profound transformations that have made it more complex and less focused on the figure of sovereign states. Notably, since of Second World War, the maintenance of peace and international security have emerged as vital needs. Thus, with the phenomenon of globalization and the emergence of new international actors, it was verified the displacement of old Westphalian anarchist system to an international set of bifurcated arrangements, based on a multicentric and interdependent society. Hence, the present article aims to analyze, through the hypothetical-deductive approach method and the technique of bibliographical research, the role played by the UN in regard to its fundamental mission for the establishment of a community of peace.

Keywords: United Nations. State sovereignty. International conflicts. Peace. Human rights.

\section{SUMÁRIO}

1 Introdução. 2 A Sociedade Internacional Clássica e o Declínio da Soberania. 3 O Segundo Pós-Guerra e suas Transformações. 4 A Organização das Nações Unidas e seus Desafios. 5 Considerações Finais. 6 Referências. 


\section{INTRODUÇÃO}

Os problemas da paz e do respeito aos direitos humanos há muito permeiam o panorama da sociedade internacional, território significativamente distinto das sociedades domésticas e dotado de uma complexidade em ascensão nunca antes vista. As inúmeras transformações pelas quais passa a comunidade internacional alteram, de fato, as demandas de cada período histórico. A paz e os direitos humanos, contudo, aparecem como uma constante, de modo que não surpreende que ambos sejam temas recorrentes nas teorias de filósofos e cientistas políticos, em especial no segundo pós-guerra.

Com efeito, a contemporaneidade nos espanta com verdadeiros paradoxos, desafios e esquizofrenias quanto à construção de uma sociedade pacífica e de respeito aos direitos humanos. Isto porque, apesar dos significativos avanços rumo à proteção dos direitos a duras penas conquistados, violações brutais ocorrem todos os dias nos inúmeros cantos do planeta. Desse modo, é mais do que necessária a progressiva (re)construção dos ideais de paz e de segurança internacionais, os quais devem ser nutridos incessantemente por meio dos múltiplos organismos internacionais, com vistas à efetivação de uma sociedade mais justa e igualitária.

A iniciativa de compreensão dos desafios preordenados pelo atual panorama internacional implica, necessariamente, a apreciação da sociedade internacional clássica (mais estável, rígida em sua estrutura e com baixos vínculos institucionais) do declínio da soberania dos Estados e da crescente interdependência global. Tal relação multicêntrica e interdependente tem respaldo no fenômeno da globalização, na relativização da soberania e, por conseguinte, no surgimento dos novos atores políticos internacionais com participação cada vez mais expressiva na sociedade contemporânea do segundo pós-guerra (mais dinâmica e integrada).

Nesse contexto, a transformação da sociedade internacional nos últimos 70 anos tem sido muito significativa, dado que o fenômeno da globalização possibilitou a aproximação entre os Estados e uma intensa unificação dos povos. Isso porque o século 21 é palco de enorme complexidade, a qual delineia os novos contornos da sociedade internacional denominada de contemporânea: não mais centrada apenas no poder e na soberania do Estado, mas também no Direito e na solução pacífica dos conflitos.

Com a emergência dos novos atores internacionais, novos pressupostos foram estabelecidos como sendo relevantes para a manutenção da paz mundial e da proteção aos direitos humanos. Desse modo, a Organização das Nações Unidas (ONU), ao lado de outras importantes instituições que visam à cooperação dos povos, apresenta-se como um organismo tendente a assegurar a paz mundial e a combater as graves violações aos direitos humanos desencadeadas na contemporaneidade pela irracionalidade dos conflitos armados, resgatando, portanto, valores como a alteridade e a empatia.

Assim sendo, são evidentes os dinâmicos processos de construção e reconstrução da sociedade internacional, o que justifica a análise realizada ao longo do presente estudo, a fim de que a questão da paz se mostre cada vez mais relevante no panorama global contemporâneo. Nesse sentido, objetiva-se, por meio do emprego do método de abordagem hipotético-dedutivo e da técnica de pesquisa bibliográfica, refletir sobre as transformações da sociedade internacional das últimas décadas e sobre o papel desempenhado pela Organização das Nações Unidas no estabelecimento de um cenário de paz duradouro. 


\section{Humanos e}

Democracia

\section{A SOCIEDADE INTERNACIONAL CLÁSSICA E O DECLÍNIO DA SOBERANIA}

A história da civilização sempre foi marcada por inúmeros conflitos, por buscas, questionamentos, antagonismos, conquistas e divergências. Sendo assim, são evidentes os processos de transformação da sociedade internacional, o que faz com que os estudos concernentes a essa temática mostrem-se cada vez mais necessários diante da crescente complexidade do cenário global contemporâneo.

Houve um período da trajetória humana em que o Estado teve o privilégio de ser a principal entidade política reconhecida - senão a única - constituindo-se como o elemento central que demarcou o surgimento da sociedade internacional clássica. Esse processo de centralização e concentração política culminou, lenta e gradativamente, no delineamento do Estado moderno soberano, o qual foi consequência da convergência de uma série de acontecimentos históricos significativos que marcaram a Idade Média, entre os quais se destacam a desagregação e o colapso do regime feudal, o declínio do papado, o florescimento do comércio, o Renascimento e a emergência da Reforma Protestante.

Em síntese, pode-se afirmar que o Estado moderno superou, lentamente, inúmeras dificuldades que foram lhe delineando. Internamente, subjugou os poderes locais dos senhores feudais, clérigos, corporações de ofício e demais ordens inferiores e, externamente, afastou a supremacia do Sacro Império Romano-Germânico, bem como as pretensões da Igreja Católica, afirmando-se como ente político soberano e independente.

Nesse contexto, a consolidação definitiva do Estado moderno soberano deu-se com a celebração, em 1648, da Paz de Westfália, a qual encerrou a Guerra dos Trinta Anos e, mais do que isso, marcou os primórdios da atual sociedade internacional, afirmando a igualdade jurídica entre os Estados e consolidando o princípio da soberania estatal. Logo, pode-se perceber que a Paz de Westfália caracteriza-se como um relevante marco histórico relativo a um vasto e complexo processo de nascimento e consolidação do Estado moderno, bem como da sociedade internacional clássica.

De acordo com os ensinamentos de Philip Bobbitt (2003, p. 477):

Da anarquia que caracterizou os derradeiros estágios da Guerra dos Trinta Anos, emergiu uma sociedade de Estados dotada de maior solidez e coerência, cuja estrutura legal foi redefinida por uma nova construção - a série de tratados conhecidos coletivamente como Paz de Westfália.

Foi com base na pretensão de melhores posições negociadoras e no objetivo de encontrar uma paz segura e duradoura, que os Tratados da Paz de Westfália possibilitaram o reconhecimento do Estado moderno, dentro de seus limites, na condição de ente soberano independente e núcleo fundamental de articulação política da emergente sociedade internacional clássica. Conforme Mark Zacher (2000, p. 84), essa sociedade é assim designada porque "reconheceu o Estado moderno como poder supremo ou soberano dentro de suas fronteiras, descartando as reivindicações transnacionais de autoridade política da Igreja [e do Império]".

Fica evidente, portanto, que a sociedade internacional clássica se configurou a partir da Paz de Westfália, que se caracteriza por ser o marco culminante de constituição e afirmação de sua unidade de articulação política central: o Estado moderno, livre de qualquer vínculo de 
dependência ou subordinação. Desse modo, essa sociedade internacional se traduz no momento em que os direitos do papa e do imperador foram substituídos pelos dos Estados, os quais se caracterizavam por serem iguais e soberanos. Sendo assim:

A Paz de Westfália constitui-se, portanto, no divisor de águas entre a sociedade internacional típica da Idade Média - centrada no poder da Igreja e no arbitramento internacional do papa - e a sociedade internacional clássica - focada no conceito de soberania dos Estados e em seus interesses (BEDIN, 2011, p. 28).

Essa soberania estatal, típica da referida sociedade internacional, fez do conflito um elemento praticamente constante, tendo predominado na maior parte desse período histórico. Para tanto, as relações entre os Estados, desde a Paz de Westfália e o início da sociedade internacional clássica (1648), até o término da Segunda Guerra Mundial (1945), caracterizou-se notoriamente como relações de poder e de preponderância da soberania absoluta.

Na referida sociedade, devido à convivência de múltiplas entidades políticas soberanas e pela primazia das relações de poder entre os Estados, inexistiam, consequentemente, formas pacíficas de solução dos conflitos. Isso se deve ao fato de que

[...] todos os Estados entendem que seus interesses e valores são mais importantes do que os interesses e valores dos demais. Assim, é criada potencialmente uma situação de permanente conflito de interesses e de eventual solução violenta. É que os Estados, não havendo uma autoridade centralizada, buscam proteger os seus interesses e valores por meio de seus próprios recursos e isto significa que podem infringir, a partir do conceito de razão do Estado, as regras mais elementares da convivência entre eles [...] (BEDIN, 2011, p. 56).

Com a afirmação dos Estados modernos, a sociedade internacional clássica, diante da falta de um poder superior, configurou-se como uma situação hipotética de guerra perpétua, quando todos os Estados detinham liberdade para fazer o que julgavam mais adequado e favorável aos seus interesses e à manutenção do poder. Essa sociedade composta por múltiplas soberanias, em que cada Estado tinha o direito de agir como bem entendesse, caracteriza-se "pela não superação do estado de natureza, que pode, inclusive, terminar em guerra (guerra de todos contra todos)" (BEDIN, 2011, p. 39).

À vista disso, pode-se afirmar que as relações da referida sociedade eram, de fato, definidas como relações anárquicas e conflituosas, uma vez que os atores internacionais não questionavam a legitimidade e a legalidade do recurso às forças armadas. Assim, o conceito de interesse nacional afirmava-se como um dos pontos principais, em que os valores jurídicos e éticos eram submetidos, tão somente, aos objetivos de poder de cada Estado. Martin Wight (2002, p. 82) chega a afirmar que a sociedade internacional clássica se caracteriza "como uma anarquia institucional - uma multiplicidade de potências sem governo".

Por conseguinte, a soberania externa dos Estados equivale, na sociedade internacional clássica, a uma liberdade selvagem que reproduz o estado de natural desregramento (FERRAJOLI, 2002). Isto gera o que Thomas Hobbes (2012) chamou de bellum omnium (guerra de todos), fazendo com que os Estados, na busca incessante pelo poder, constituam-se como verdadeiros "leviatãs", permanentemente dispostos à guerra, ou seja, um evidente estado de natureza. 


\section{Humanos e \\ Democracia}

Nesse período inexistiam formas pacíficas de resolução dos conflitos. O poder político dos Estados se materializava de duas maneiras: pela diplomacia e pela guerra. As relações interestatais, portanto, consistiam em uma luta pelo poder e pela preservação dos interesses nacionais, dado que tais unidades políticas independentes não reconheciam superior político e consideravam-se soberanas.

Desse modo, o sistema de equilíbrio ou de balança de poder entre as diversas potências, ao frear e estabilizar as relações de poder, configurou-se como um substituto de uma autoridade supranacional inexistente. Este sistema era considerado o "único recurso aceito pelos Estados soberanos como legítimo para o estabelecimento de um cenário de paz duradoura" (BEDIN, 2001, p. 352). Assim, percebe-se que o equilíbrio de poder se configura numa clara tentativa de estabelecer a paz nas relações entre os Estados da sociedade internacional clássica.

A aludida soberania dos Estados modernos, aliada ao incremento massivo do poderio e da capacidade bélica das nações, culminou - e nem poderia ser diferente - nas duas grandes guerras mundiais. Isso posto, portanto, pode-se afirmar que o modelo dos Estados soberanos permaneceu intacto até meados do século 20 , quando então ocorreram profundas alterações nas relações internacionais.

Nesse contexto, merece especial atenção o megaconflito bélico da Segunda Guerra Mundial, o qual perdurou de 1939 a 1945, envolvendo a maior parte das nações do mundo, as quais estavam organizadas em duas alianças militares opostas: os Aliados (liderados pelos Estados Unidos, Grã-Bretanha e União Soviética) e as Potências do Eixo (Alemanha, Itália e Japão). Os principais envolvidos empreenderam toda sua capacidade econômica, científica e industrial na guerra, de tal modo que foi considerado o confronto armado mais abrangente e letal da história da humanidade, muito lembrado pelas trágicas violações aos direitos humanos (TOTA, 2011).

De fato, a Segunda Guerra Mundial foi um conflito sangrento que ocasionou danos irreparáveis à humanidade. $O$ racismo esteve presente e deixou uma ferida grave, principalmente na Alemanha, país em que os nazistas cometeram o holocausto - matando nos campos de concentração aproximadamente 6 milhões de judeus, homossexuais, negros, ciganos e prisioneiros de guerra - com o objetivo de garantir a superioridade da raça ariana. Assim, esta guerra deixou um rastro de morte, destruição, diversas cidades em ruínas e dívidas incalculáveis, além dos indivíduos que restaram feridos, mutilados, sem moradia e família. Para Martin Gilbert (2009, p. 11):

A Segunda Guerra Mundial conta-se entre os conflitos mais devastadores da história da humanidade: mais de quarenta e seis milhões de militares e civis pereceram, muitos deles em circunstâncias de uma crueldade prolongada e terrível. Nos 2.174 dias de guerra, que decorreram entre o ataque da Alemanha à Polônia em setembro de 1939 e a rendição do Japão em agosto de 1945 [...] não foram apenas quarenta e seis milhões de vidas que foram aniquiladas, mas a vida e a vitalidade vibrantes que elas tinham [...]

Tal conflito terminou tão somente em 1945, com a rendição da Alemanha e da Itália. O Japão foi o último país a se render, sofrendo um intenso ataque por parte dos Estados Unidos. Por isso, a Segunda Guerra foi um confronto total no sentido lato da expressão, tendo em vista os sofisticados mecanismos empregados, a exemplo das bombas atômicas utilizadas pelos 
Estados Unidos para atingir as cidades japonesas de Hiroshima e Nagasaki. O alcance de tais armas provocou - e ainda provoca - um intenso e constante medo, ameaçando o mundo com uma nova tecnologia de morte e destruição em massa.

Posteriormente à guerra, o mundo iniciava uma nova fase histórica clamada pela humanidade: a de reconstrução. O fim do conflito internacional marcou o encerramento da hegemonia europeia e deflagrou a disputa entre o Ocidente, liderado pelos Estados Unidos (EUA), e o bloco socialista, liderado pela União Soviética (URSS), anunciando os primeiros indícios da guerra fria.

Ressalta-se que nesse contexto de pós-guerra foi fundada a Organização das Nações Unidas (ONU), em 1945, e promulgada a Declaração Universal dos Direitos Humanos, em 1948 , que se consolidaram como marcos históricos significativos e cruciais para a mudança paradigmática das relações interestatais, tendo claramente definidos os objetivos de manter a paz, a segurança internacional entre as nações e garantir a proteção dos direitos inerentes a todos os seres humanos. Além disso, pode também ser evidenciado o claro objetivo de limitar a soberania dos Estados e de romper com os paradigmas da sociedade internacional clássica (BEDIN, 2001).

Diante disso, na sociedade internacional "a soberania do Estado deixa de ser uma liberdade absoluta e selvagem e, se subordina, juridicamente, a duas normas fundamentais: o imperativo da paz e a tutela dos direitos humanos" (FERRAJOLI, 2002, p. 39). No que concerne a essa soberania estatal, o jurisfilósofo Hans Kelsen (2011, p. 33) já entendia que, no âmbito internacional, ela é relativa e não absoluta, conforme preceitua:

[...] A soberania dos Estados, como sujeitos de direito internacional, é a autoridade jurídica dos Estados sob a autoridade do direito internacional. Se soberania significa autoridade "suprema", a soberania dos Estados como sujeitos de direito internacional não pode significar autoridade suprema absoluta, mas tão somente uma autoridade suprema relativa [...].

A configuração tradicional das relações internacionais da sociedade moderna encontra-se, nesse momento, em uma fase de esgotamento histórico, o que produz, consequentemente, uma grande crise construtiva. "É que se vive, na verdade, um momento de declínio da sociedade típica do mundo moderno - centrada no Estado soberano e no sistema de equilíbrio de poder" (BEDIN, 2001, p. 264). Isto significa que a atual sociedade internacional adquiriu, no segundo pós-guerra, aspectos de uma comunidade institucional, com características menos anárquicas e conflituosas, mas mais interdependentes e voltadas à solução pacífica dos conflitos.

Por conseguinte, enquanto a sociedade internacional foi evoluindo para o estabelecimento gradativo de uma espécie de comunidade de direitos mais claramente delineada, o cenário começa, lentamente, a ser modificado e os conflitos centrados no convívio de várias soberanias começam a ser relativizados. Essa transformação tem grandes implicações e permite a afirmação de que a paz e os direitos humanos tornaram-se temas globais à maneira kantiana. 


\section{Humanos e}

Democracia

Isso significa que tais direitos passaram a representar, conforme Celso Lafer (2006, p. 148-149), o "reconhecimento axiológico do ser humano como fim e não como meio, tendo direito a um lugar no mundo", o que reforçou, de fato, a ideia de pacificação universal. Daí, portanto, passou a ser necessária a manutenção da paz por meio do direito em caráter global, independentemente de quaisquer circunstâncias, tutelando-se a dimensão humana presente em todos os indivíduos.

\section{O SEGUNDO PÓS-GUERRA E SUAS TRANSFORMAÇÕES}

Diante do novo cenário emprestado à sociedade internacional a partir da segunda metade do século 20 e do início do século 21, que agora passa a tomar forma de uma verdadeira comunidade global, as relações internacionais apresentam relevante complexidade, polaridade incerta e um evidente vínculo de cooperação e interdependência entre os principais atores internacionais. Tais mudanças acarretaram na fragilização e no declínio da sociedade internacional clássica, alicerçando novas possibilidades e alternativas mundiais integradas, bem como colaborando para a construção de uma nova ordem mundial mais justa e solidária: a sociedade internacional contemporânea, delineada sucintamente por Bedin (2001, p. 352) nos seguintes termos:

De uma certa maneira, com as transformações das últimas décadas, ruíram todos os pilares de referência da sociedade internacional clássica, pois as relações que ainda se chamam de internacionais - mas que deveriam ser chamadas de transnacionais - adquiriram crescente complexidade em seus diversos aspectos, polaridade incerta entre os seus principais atores e o estabelecimento de vínculos de interdependência e de cooperação nunca antes imaginados. Por isso, pode-se afirmar que a sociedade internacional clássica entrou em declínio e que em seu lugar surgiu uma nova sociedade internacional [...] que se encontra, ainda, em profunda transformação.

Nesse panorama de modificações, a humanidade presenciou o constante deslocamento do velho sistema anárquico - centrado no Estado e na sua soberania - para uma nova conjuntura internacional de arranjos bifurcados, assentada em um mundo multicêntrico e interdependente, composta por várias coletividades dispostas à integração e à cooperação num sistema mundial globalizado, mais integrado e institucionalmente regulamentado. Em virtude dessas transformações,

[...] o conceito de soberania externa começa a entrar em declínio e, em consequência, novas relações se estabelecem entre os Estados. Desta forma, o velho mundo de Westfália (centrado na soberania absoluta do Estado) vai sendo deixado para trás, passando a ser valorizados novos temas e novos atores (principalmente de organizações internacionais e organizações não governamentais). Com isto, passa a se conformar também uma nova fase do Direito Internacional (BEDIN, 2011, p. 10).

Após a Segunda Guerra Mundial o desenho conferido à recente conjuntura social contemporânea possibilitou a configuração de uma nova realidade, com a conformação de alternativas planetárias mais integradas e avançadas no âmbito das relações internacionais. Esta circunstância revela que o mundo tem oscilado entre a defesa da política de poder e a adesão de formas mais institucionalizadas para a mediação dos conflitos. 
Foi, sobretudo, a emergência de novos atores internacionais no segundo pós-guerra que determinou o declínio da sociedade internacional clássica. Desse modo, assiste-se no momento atual à conformação de uma nova ordem mundial, protagonizada pela coexistência dos Estados e de tais atores, bem como pelo delineamento e formulação das novas possibilidades e modelos teóricos paradigmáticos. Entre esses novos atores internacionais merecem destaque as organizações internacionais, as Organizações Não Governamentais e as empresas transnacionais.

As organizações internacionais, também chamadas de organizações intergovernamentais, podem ser entendidas como sendo instituições internacionais criadas consensualmente pelos Estados soberanos e que têm por objetivo a cooperação e melhoria das condições dos seus integrantes de um modo geral. As Organizações Não Governamentais são aquelas criadas pela sociedade civil, mediante a associação voluntária dos indivíduos, ou seja, não são estruturas alicerçadas nos Estados. Surgem, portanto, na falha da estrutura estatal justamente a fim de suprir as deficiências não sanadas pelo governo. Por sua vez, as empresas transnacionais possuem matriz em um dado país, tendo atuação em outros mediante instalação de inúmeras filiais.

Fica evidente que a crescente complexidade e interdependência da sociedade internacional contemporânea derivam, justamente, do surgimento dos novos atores internacionais. Essa atual conjuntura social ruiu com as características basilares da sociedade internacional clássica, dado que existe uma predisposição voltada ao fortalecimento das interconexões globais, as quais aproximam os laços entre os países e, cada vez mais, relativizam a lógica restritiva das fronteiras nacionais.

Desta forma, a crescente interdependência tem traçado em meio às fronteiras estatais múltiplos canais entre as mais distintas nações, com o intuito de mediar e solucionar os problemas de ordem internacional. Ademais, vale destacar que este cenário preparou a emergência de um acontecimento intenso e com dimensões bastante abrangentes, o qual se constituiu no mais relevante evento político, econômico e social das últimas décadas: o fenômeno da globalização do mundo.

De fato, não resta a menor dúvida de que a configuração do planeta como um sistema global consiste num dos mais expressivos acontecimentos da História humana. Desse modo, o fenômeno da globalização caracteriza-se por ser a causa e o efeito, simultaneamente, da unificação do planeta em todos os sentidos e com diversos graus de intensidade. Assim sendo, faz-se coerente a afirmação de Milton Santos (1997, p. 48) de que "a Terra torna-se um só e único 'mundo' e assiste-se a uma refundição da totalidade-terra”.

Assim, nesse contexto da globalização, assiste-se

[...] à redução das distâncias, à aceleração do tempo, à quebra das identidades nacionais, à ruptura das fronteiras e à conformação de novas relações políticas. Com isto, é gerado um novo horizonte de sentido para a vida na Terra e produzido um rompimento das relações internacionais centradas apenas nos Estados e no conceito de soberania (BEDIN, 2011, p. 130). 


\section{Democracia}

À vista dessa mudança histórica fundamental, evidencia-se que a globalização, além de se constituir como marco simbólico-referencial da emergência do século 21 , também dá início ao processo de consolidação de uma nova e complexa fase da sociedade internacional. Desse modo, vive-se atualmente num mundo que se caracteriza "pelo aparecimento de um conjunto de possibilidades concretas, que modificam equilíbrios preexistentes e procuram impor sua lei [e suas determinações]" (SANTOS, 1997, p. 48).

Fato é que o novo século 21 traz à tona um intenso paradoxo jamais vivido em âmbito mundial: por um lado, evidencia-se o extraordinário avanço das renovadas e complexas tecnologias; por outro, destaca-se a contradição existente na mundialização da vida humana, pela qual dois opostos se atraem inevitavelmente - a homogeneização política, econômica e cultural almejadas pelas elites dominantes, bem como a desagregação dos centros de referência da sociedade internacional, cujas fronteiras são mais facilmente permeáveis e transponíveis. Nesse sentido, Bedin (2014, p. 32) destaca que

[...] tanto quanto os últimos séculos da história humana foram dominados por problemas relacionados com o surgimento, a construção e a supremacia dos Estados-nação, o início do século XXI está envolvido com o surgimento e a consolidação de fluxos que não respeitam fronteiras. Em outras palavras, está preocupado com os problemas oriundos da emergência e da estruturação do domínio da política e da economia mundiais.

Por conseguinte, pode-se afirmar que noção de espaço é redefinida, visto que as distâncias são reduzidas e o mundo adquire um novo status: "de território comum da humanidade" (BEDIN, 2014, p. 33). Dessa forma, as mudanças que afetam as civilizações podem, de fato, serem sentidas em toda parte do globo, isso porque, conforme Octavio lanni (1996, p. 169-170), por meio do fenômeno da globalização, o planeta transformou-se

[...] em um território de todo o mundo. Tudo se desterritorializa e reterritorializa. Não somente muda de lugar, desenraíza-se circulando pelo espaço, atravessando montanhas e desertos, mares e oceanos, línguas e religiões, culturas e civilizações. As fronteiras são abolidas ou tornam-se irrelevantes ou inóquas, fragmentam-se e mudam de figura, parecem, mas não são [...].

Nesse contexto, com o impacto direto da era da globalização, a soberania e a autonomia dos Estados são relativizadas e fragilizadas pelo extraordinário aumento das interconexões globais, constituindo esta uma característica estruturante da sociedade internacional contemporânea. Por tais razões, discorrendo sobre a pluralidade de conflitos oriundos desse fenômeno, Ferrajoli (2002, p. 49-50) preceitua que:

De fato, paradoxalmente, são justamente a rapidez e a multiplicidade das comunicações que acentuaram o anseio de identidade dos povos, das etnias, das minorias e, ao mesmo tempo, o valor associado às diferenças, acendendo conflitos étnicos desagregadores dentro das fronteiras dos Estados e processos inversos de integração nacional fora delas [...]

É verificável que se anteriormente os confrontos eram marcados pelo caráter estritamente local, na contemporaneidade esses embates dizem respeito não somente à região na qual ocorre a disputa, mas a todas as demais nações que compõem a aldeia global, atingindo 
um número indeterminado de pessoas. Assim, com a globalização dos conflitos e da violência, torna-se necessária a proteção universal dos direitos humanos na comunidade internacional da maneira mais abrangente possível.

Fato é que, mesmo diante da globalização, o Estado moderno não chegou a desaparecer e provavelmente não desaparecerá abruptamente. É prudente reconhecer, todavia, que a autonomia e a soberania estatais cedem poder a outros órgãos, instituições e entidades menos soberanos e mais integrados num projeto comum, cujo fundamento basilar reside no fato de que os problemas são interdependentes e globalizados, de modo que interessam a todos os homens e não apenas a grupos isoladamente considerados da humanidade.

\section{A ORGANIZAÇÃO DAS NAÇÕES UNIDAS E SEUS DESAFIOS}

Os antagonismos, paradoxos e incoerências existentes na sociedade internacional exigiam, de fato, uma solução pacífica eficaz. Surge, então, a proposta da constituição de organismos internacionais capazes de estabelecer uma paz duradoura para reparar, na medida do possível, todo o sofrimento e o horror a que foi submetida a humanidade nos 2.174 dias da Segunda Guerra. Desse modo, "o organismo pensado para coordenar as diretrizes para a manutenção da paz foi a Organização das Nações Unidas (ONU)" (TOTA, 2011, p. 387). Fica evidente, portanto, que com o término da Segunda Guerra Mundial, tornou-se necessária a criação de mecanismos voltados à proteção dos direitos humanos e à construção de uma comunidade de paz por meio do Direito, não somente em esfera local, mas em todo âmbito universal.

Nesse sentido, Norberto Bobbio (2009, p. 11) já afirmava que "se alguém me perguntar quais são, na minha opinião, os problemas fundamentais do nosso tempo, não tenho qualquer hesitação em responder: o problema dos direitos do homem e o problema da paz". Por conseguinte, à medida que a sociedade internacional se tornou cada vez mais universal até chegar a abraçar todos os povos da Terra, universalizou-se a falta de segurança, a necessidade da pacificação mundial e a urgência pela proteção internacional dos direitos inerentes a todos os seres humanos.

Além disso, a deflagração da Segunda Guerra Mundial (1939-1945) desvendou os extremos que podem ser alcançados quando se une o conflito bélico a intensos artefatos tecnológico-militares. O fenômeno da guerra, que para Carl Von Clausewitz (1996) consolida-se na realização da política por outros meios, torna-se - com o advento dos governos totalitaristas e das armas nucleares - a essência de novas e terríveis possibilidades: a rendição e a destruição maciça de civilizações inteiras e, também, da própria vida existente no planeta. Assim, as novas e destrutivas tecnologias empregadas na guerra demonstraram até que ponto os antagonismos e as rivalidades estatais westfalianas podem chegar quando vinculadas aos exacerbados nacionalismos evidenciados num panorama de desequilíbrios políticos, econômicos e sociais.

Dessa forma, a criação de uma organização internacional direcionada à manutenção da paz e do diálogo entre as nações no segundo pós-guerra foi um dos imperativos colocados para as principais potências mundiais. É que se constatou que as consequências políticas, hu- 


\section{Humanos e}

Democracia

manas e econômicas da guerra eram inaceitáveis e que as soberanias dos Estados deveriam ser mediadas e limitadas por novas estruturas institucionais, tornando-se evidente que uma cooperação maior entre as nações significa mais êxito na resolução pacífica das controvérsias.

É irrefutável que o mais relevante antecedente histórico da Organização das Nações Unidas consiste na Liga das Nações. Após os profundos impactos políticos, econômicos e sociais, além dos desgastes das estruturas estatais ocasionados pela Primeira Guerra Mundial, surgiu uma necessidade imediata de paz que resultou na criação da Liga das Nações, em 1919, com o Tratado de Versalhes. Sendo assim, consoante o entendimento Renata de Melo Rosa (2016, p. 90, grifo da autora):

A convergência para a obediência aos estatutos e Tratados e não a determinadas potências e impérios marcou esta nova diplomacia e estruturou as raízes do multilateralismo institucional. No entanto, os chamados Vinte Anos de Crise, que foram de 1919 a 1939, momento embrionário de institucionalização da política mundial, também coincidiu com o período entreguerras [...]

O fracasso da Liga das Nações - criada sob a égide de uma aliança de paz - foi progressivo e inevitável. Com o desencadear do segundo maior conflito armado, tal organização internacional não atingiu, definitivamente, o seu objetivo de promover a paz e a igualdade de cooperação entre os Estados soberanos em âmbito global.

A Liga entendia que comportamentos agressores não seriam tolerados. Dessa forma, Japão e Alemanha se retiraram da entidade em 1933, Itália, em 1937, e União Soviética em 1939. Todos eles haviam se envolvido em invasões territoriais fortemente condenadas no Estatuto da Liga [...]. O período de seis anos que englobou o intervalo de 1933 a 1939, no qual a Liga perdeu quatro de seus membros, aqueles mesmos Estados que iriam protagonizar a Segunda Guerra Mundial, houve um rápido deterioro do institucionalismo liberal e de seu potencial para comprometer os Estados a obediências às leis, estatutos e decisões colegiadas. O comportamento hobbesiano destes Estados, ou anárquico nos termos do realismo clássico na busca de mais poder territorial regional, fez eclodir um conflito de interesses extremamente sangrento que caracterizou a Segunda Guerra Mundial (ROSA, 2016, p. 90-91).

No cenário do segundo pós-guerra, portanto, com vistas à cooperação dos Estados para a manutenção da paz mundial e do respeito aos direitos humanos, a ONU foi criada em 24 de outubro de 1945. Há mais de 70 anos, essa organização de caráter universal, da qual participam atualmente 193 Estados-membros, coloca-se como pilar sustentador das relações internacionais (NAÇÕES..., 2017). Tal fato possibilita que a ONU exerça um papel imprescindível e insubstituível, atuando como único fórum de diálogo entre as nações, com o objetivo de tornar o mundo mais seguro e permitir a coexistência pacífica dos povos.

Assim sendo, a Carta das Nações Unidas, nascida dos escombros da Segunda Guerra Mundial e sob o auspício da Liga das Nações, se constituiu num pressuposto fundamental sobre o qual se construiu um importante espaço institucional de diálogo para a manutenção da paz e da segurança internacional: a Organização das Nações Unidas. Nesse sentido, é importante destacar que essa entidade foi criada após um longo processo de negociações, as quais evidenciaram rapidamente o quanto seria difícil o trabalho dessa grande organização. 
Apesar das dificuldades iniciais, a Organização das Nações Unidas foi, aos poucos, consolidando o seu trabalho. De fato, do apoio à independência das nações colonizadas pelos povos europeus, nos seus primeiros anos, passando pelo amparo aos temas de ordem política, econômica e social nos países de Terceiro Mundo, até os constantes e intensos ataques à sua inoperância em questões consideradas fundamentais durante o período da guerra fria, a ONU foi se afirmando no cenário internacional e se consolidando nas últimas décadas, apesar de suas limitações, como um dos poucos fóruns de diálogo entre os Estados.

Atualmente a ONU apresenta uma estrutura bastante complexa, o que torna indispensável a necessidade de discorrer brevemente a respeito da sua composição. Constituída por seis órgãos principais, os quais desempenham atividades administrativas, deliberativas e decisivas, tem-se que:

1. O principal órgão administrativo é o Secretariado;

2. já a Assembléia Geral, o Conselho Econômico e Social e, anteriormente, o Conselho de Tutela, são foros deliberativos em suas respectivas competências;

3. finalmente, apenas dois órgãos possuem o poder de adotar decisões juridicamente obrigatórias para os seus membros: o Conselho de Segurança e a Corte Internacional de Justiça (LASMAR; CASARÕES, 2006, p. 13).

A Assembleia Geral e o Conselho de Segurança são os principais órgãos, a primeira com as suas resoluções (recomendações) de caráter não obrigatório, enquanto o segundo, principal órgão de debate e decisões políticas, é composto por um total de 15 Estados-membros, dos quais 5 desses são permanentes e têm poder de veto (Estados Unidos da América, Reino Unido, França, Rússia e China) e os outros 10 são membros rotativos não permanentes eleitos pela Assembleia Geral para um período de dois anos.

É incontestável que a missão da ONU ficou clara desde o primeiro momento: construir um cenário de paz duradouro na sociedade internacional e instituir medidas tendentes à administração dos problemas relativos à violação dos direitos humanos. Em que pesem o avanço e as conquistas dessa organização, tem-se, paralelamente, o enfrentamento de inúmeras dificuldades ao lidar com uma realidade conflituosa, em que as normas jurídicas internacionais são frequentemente negligenciadas e até mesmo flagrantemente violadas.

Nesse contexto, é notório que uma maior cooperação entre os Estados em relação às Nações Unidas significa mais êxito na proteção internacional dos direitos e na consequente manutenção da paz. Assim sendo, no que diz respeito à atuação dos Estados, é "inútil e pouco sério continuar a lamentar a ineficiência da instituição e depois contribuir, com o próprio comportamento, para o crescimento dessa ineficiência" (BOBBIO, 2009, p. 291) na medida em que descumprem as disposições estabelecidas pela ONU. Por outro lado, não se pode deixar de referenciar que:

A liberdade de ação que o Conselho de Segurança se autoatribuiu no que tange ao arbítrio de seu próprio julgamento e decisão acerca da "ação que julgar necessária" para o retorno ao status quo dos Estados territoriais que compõem o sistema westfaliano, ocasionou, na prática, o efeito contrário [...]. A intervenção a territórios soberanos esbarra 


\section{Humanos e \\ Democracia}

na questão de fundo que baliza a raiz da dificuldade de acertos da ONU: como legitimar o desmonte do sistema westfaliano que estrutura o sistema internacional? (ROSA, 2016, p. 92-96).

Assim, fica evidente que a resistência dos Estados à ação intervencionista humanitária da ONU constitui o principal motivo do fracasso das missões de paz. Não basta, para o estabelecimento da paz e da proteção dos direitos, armar a ONU sem desarmar os Estados, tendo em vista que "as forças atualmente em poder destes são, sozinhas, suficientes para destruir várias vezes o planeta, e nenhuma força supranacional é suficiente para refreá-las" (FERRAJOLI, 2002, p. 56). Este é o grande desafio do mundo atual: retirar dos Estados o poder de decidir isoladamente sobre a guerra.

Além disso, é importante ressaltar que "não há dúvidas de que os países envolvidos em conflitos armados são frágeis, mas a resposta da ONU a esta fragilidade é a aprovação de inúmeras resoluções, sem que os conflitos internos diminuam os seus patamares de violência" (ROSA, 2016, p. 101). É em virtude dessas peculiaridades que alguns estudiosos como Alexandre Almeida e Jefferson Ubiratan (2012) vêm se posicionando no seguinte sentido:

Se por um lado a sua instituição pode ser considerada como um avanço no que diz respeito à integração das Nações, por outro ela não passa de um "tigre de papel", designação dada pelo teórico alemão [...] Jürgen Habermas para a atuação da ONU no plano global. O que tem sido observado é que as Nações Unidas não possuem meios eficazes para impedir que um membro permanente do Conselho recorra à força armada, contando apenas com a sua boa vontade em relação à paz.

Na mesma senda, o jornal britânico The Guardian, na reportagem especial intitulada "70 years and half a trillion dollars later: what has the UN achieved?", questionou as forças ocultas por trás da organização - especialmente no que diz respeito às grandes potências comparando inclusive o poder de veto dos cinco membros permanentes do Conselho de Segurança ${ }^{1}$ a mãos com um chicote (MCGREAL, 2015). Esse posicionamento vai ao encontro do pensamento de Celso Lafer (2006, p. 175):

De qualquer modo, as iniciativas da ONU capazes de repercutir em grau relevante e de maneira mais direta na ordem internacional devem contar com o respaldo dos países poderosos. Na falta desse apoio, as iniciativas da ONU não têm condições de prosperar, ao menos de modo mais imediato. Daí a percepção popular de que a ONU ou é um instrumento dos países mais poderosos ou é um organismo ineficaz, que produz quantidades de documentos que caem no vazio. Embora seja esta uma visão simplista, podemos dizer que há algo de verdadeiro nela, no sentido de que a ONU não é melhor ou mais poderosa do que os Estados que a compõem.

Apesar de todas as críticas, pode-se afirmar que a Organização das Nações Unidas, na condição de principal instituição política de alcance mundial existente tem cumprido um papel fundamental na manutenção da paz. Isto significa que desde o término da Segunda Guer-

Estados Unidos, França, Inglaterra, Rússia e China. 
ra Mundial a ONU conseguiu produzir um mundo menos belicoso e tem sido efetiva, em boa medida, na solução pacífica dos conflitos internacionais. Não obstante, sendo esta organização entendida como o mais importante fórum de diálogo mundial, considera-se que

[...] o investimento em "operações de paz" não militarizadas, voltadas para os mecanismos de interpretação dos conflitos a partir de bases da compreensão da intersubjetividade dos atores envolvidos pode ser um importante instrumento de promoção de soluções negociadas com atores locais e um caminho mais seguro para a efetiva construção da paz. Nesse sentido, o reforço a uma metodologia compreensiva com foco no diálogo intersubjetivo entre os representantes do Estado local, da ONU, das organizações regionais e de variados setores da comunidade afetada por conflitos armados pode ser mais promissora a longo prazo do que uma intervenção militar cuja metodologia segue um único padrão descontextualizado das variáveis locais (ROSA, 2016, p. 102).

Desse modo, não se pode negar que "em face dessa realidade, uma instituição como a ONU [...] tem alguma capacidade de dar rumo à correção dos desequilíbrios mais graves e relativos à paz, ao desenvolvimento e aos direitos humanos" (LAFER, 2006, p. 173). Afinal, se um mundo com a ONU já é conflituoso o suficiente, não queiramos nós imaginar um mundo sem esta organização internacional. Isso significa que embora existam algumas ineficiências, a ONU, sem dúvida, é um ente essencial na disseminação de ideais éticos, de paz mundial e de respeito aos direitos humanos.

Assim, a ONU não se trata de um organismo internacional inútil, tampouco consiste numa solução definitiva visando à paz perpétua idealizada por Kant (2004). Dessa forma, é preciso lembrar que o impetuoso desejo por paz e segurança, fundamental na constituição desta organização internacional, é o mesmo que animou os homens, segundo Hobbes (2012), a criar o Leviatã de poder absoluto. É evidente, portanto, a necessidade de uma mudança da concepção de cultura reacionária para uma cultura preventiva entre os Estados. Isso porque apenas essa perspectiva será capaz de propiciar a duradoura paz almejada pelos povos, principalmente por aqueles que já sofreram e foram dilacerados pela violência e pelos flagelos da guerra.

\section{CONSIDERAÇÕES FINAIS}

O presente artigo teve como preocupação fundamental a análise de alguns aspectos atinentes à sociedade internacional clássica e contemporânea. Abordou-se, também, a missão fundamental da ONU no estabelecimento gradativo de uma comunidade de paz e de respeito aos direitos humanos. Essa temática é bastante recorrente e o seu debate está longe de uma conclusão definitiva, de modo que nos resta, tão somente, a certeza de que a história vivida jamais se apagará, encarregando-se o presente da construção de um futuro melhor.

É possível afirmar que apesar de as experiências típicas da sociedade internacional clássica ainda estarem presentes na pós-modernidade, muitos aspectos próprios daquela conjuntura ficaram a ela restritos, pois o Estado centralizava todo o poder, constituindo-se no único ator efetivamente relevante nas relações internacionais. Atualmente, contudo, a soberania estatal vem sendo significativamente relativizada em virtude do fenômeno da globalização, fazendo das fronteiras institutos cada vez menos rígidos. Isto é, delineia-se um novo cenário de extrema interdependência entre todas as nações do globo. 


\section{Humanos e \\ Democracia}

A própria dinâmica da evolução que impulsiona a trajetória humana faz com que a problemática da paz não perca atualidade tendo em vista os novos contextos da convivência humana e do ambiente mundial. Nesse sentido, portanto, as relações de poder não são mais um privilégio dos Estados, orbitando também entre os chamados novos atores internacionais, os quais emergem com considerável grau de influência na contemporaneidade, entre os quais citam-se: as organizações internacionais, as empresas transnacionais e as Organizações Não Governamentais. Neste estudo optou-se por emprestar especial atenção à ONU, na medida em que, apesar das críticas contra ela desferidas, tal organização ainda se apresenta com relativa efetividade no que diz respeito à difícil - senão impossível - tarefa de instauração de uma comunidade de paz duradoura em esfera global.

Vale ressaltar que os conflitos da contemporaneidade alcançam todas as dimensões do planeta e são, portanto, capazes de atingir um número indeterminado de pessoas. Assim, com a globalização dos conflitos e da violência, a criação da ONU tornou-se um fato relevante e que sinaliza para a necessidade do estabelecimento de padrões normativos claros, vinculados aos direitos humanos e à manutenção da paz na sociedade internacional da maneira mais abrangente possível.

A criação da Organização das Nações Unidas revela, de certa maneira, a percepção dos Estados de que o mundo, a partir desse momento, encontra-se unido, tendo como objetivos fundamentais a construção de novos caminhos de paz e de segurança entre as nações. Por isso, a proibição do uso da força é, na atualidade, o princípio básico do Direito Internacional do segundo pós-guerra.

Nesse contexto, Bobbio (2003) pressupõe que o único caminho para eliminar as guerras e promover uma paz duradoura e universal consiste na instituição de um superestado mundial, todavia, diante da sua inexistência o uso da força torna-se um instrumento cada vez mais difundido na sociedade internacional. Por isso, Jürgen Habermas (1999) sustentou, em especial, que as questões relativas à preservação da paz mundial e da tutela dos direitos humanos não podem ser deixadas, tão somente, nas mãos dos Estados nacionais, devendo, portanto, ser confiadas cada vez mais a organismos supranacionais.

Verifica-se que o conceito de soberania estatal passa a perder a sua faceta arbitrária e se institui, de fato, uma relação de interdependência substancial. Daí a necessidade da presença de instituições internacionais pautadas no reconhecimento da humanidade do homem, dado que este consiste num dos pressupostos fundamentais para a construção de uma ordem internacional justa e solidária. Por isso, os elementos que marcam os limites de atuação dos Estados westfalianos precisam ser reconsiderados num projeto mundial de mútuo reconhecimento e de responsabilidade, de tal modo a possibilitar a afirmação de ações concretas impulsionadoras da universalização da paz e dos direitos humanos.

Certo é que por mais impossível que possa parecer a instauração de uma sociedade internacional como um lugar comum de paz e de respeito aos direitos humanos, a civilização somente pode alcançar o verdadeiro progresso quando um ser humano, considerado em sua singularidade, sentir-se efetivamente responsável pela humanidade do Outro, enquanto igual e diferente, onde quer que ele esteja. Trata-se, então, de executar efetivamente o imperativo categórico de Kant (2004), no sentido de que é preciso agir com base em princípios cuja aplicabilidade universal se deseja. 
Uma comunidade mundial pautada na prosperidade, na democracia e na paz perpétua é, na verdade, uma grande hipótese, mas não caminhos de mão única. Fato é que, por mais utópico que possa parecer um mundo em que somente a paz prevaleça, é preciso tentar caminhar nessa direção, sendo essencial que a humanidade una todas as suas forças para construir uma sociedade pacífica e livre de controvérsias.

Não é possível afirmar, entretanto, que as dificuldades não se farão presentes nesse trajeto, mas elas não podem ser vistas como barreiras intransponíveis na busca por uma sociedade internacional pacífica, tão necessária e tão almejada. De qualquer forma, não podemos perder a esperança na manutenção da paz mundial, uma vez que a sua preservação é dever de todos aqueles que acreditam no futuro da humanidade. Assim, não se pode voltar à barbárie, ou seja, a uma conformação social desprovida de sonhos para uma vida melhor, sem valores sociais que possam estabelecer vínculos de solidariedade referenciados num projeto pacífico universal.

\section{REFERÊNCIAS}

ALMEIDA, Alexandre; UBIRATAN; Jefferson. Combater o terrorismo e preservar os direitos humanos (Reportagens). In: O Mundo: comunicação internacional. Belo Horizonte: PUC Minas, 2012. Disponível em: http://www. fca.pucminas.br/omundo/combater-o-terrorismo-e-preservar-os-direitos-humanos/. Acesso em: 18 dez. 2019. BEDIN, Gilmar Antonio. A sociedade internacional e o século XXI: em busca da construção de uma ordem judicial justa e solidária. Ijuí: Editora Unijuí, 2001.

BEDIN, Gilmar Antonio. A sociedade internacional clássica: aspectos históricos e teóricos. ljuí: Editora Unijuí, 2011.

BEDIN, Gilmar Antonio. A Idade Média e o nascimento do Estado moderno: aspectos históricos e teóricos. Ijuí: Editora Unijuí 2013.

BEDIN, Gilmar Antonio. A sociedade atual e seus grandes desafios: o papel do conceito de trabalho decente e de dignidade humana no mundo do trabalho globalmente constituído. In: Revista Eletrônica da Faculdade de Direito da Universidade Federal de Pelotas (Ufpel), Pelotas: Ufpel, n. 1, p. 32-50, 2014. Disponível em: http:// periodicos.ufpel.edu.br/ojs2/index.php/revistadireito/article/view/4980/3951. Acesso em: 14 ago. 2017.

BOBBIO, Norberto. O problema da guerra e as vias da paz. Tradução Álvaro Lorencini. São Paulo: Unesp, 2003.

BOBBIO, Norberto. $O$ terceiro ausente: ensaios e discursos sobre a paz e a guerra. Tradução de Daniela Versiani. São Paulo: Manole, 2009.

BOBBITT, Philip. A guerra e a paz na história moderna: o impacto dos grandes conflitos e da política na formação das nações. Tradução Cristiana Serra. Rio de Janeiro: Campus, 2003.

CLAUSEWITZ, Carl Von. Da Guerra. São Paulo: Martins Fontes, 1996.

FERRAJOLI, Luigi. A soberania no mundo moderno: nascimento e crise do Estado nacional. Tradução Carlo Coccioli e Márcio Lauria Filho. São Paulo: Martins Fontes, 2002.

GILBERT, Martin. A segunda guerra mundial. Tradução Ana Luísa Faria e Miguel Serras Pereira. Córdova: Dom Quixote, 2009.

HABERMAS, Jürgen. Eurocentrismo, Europa dos mercados ou Europa dos cidadãos (do mundo). Rio de Janeiro: Tempo Brasileiro, 1999.

HOBBES, Thomas. Leviatã: ou matéria, forma e poder de um estado eclesiástico e civil. Tradução Rosina D’Angina. 2. ed. São Paulo: Martin Claret, 2012.

IANNI, Octavio. Teorias da globalização. Rio de Janeiro: Civilização Brasileira, 1996.

KANT, Immanuel. Para a paz perpétua, um esboço filosófico. In: GUINSBURG, J. et al. A paz perpétua, um projeto para hoje. São Paulo: Perspectiva, 2004.

KELSEN, Hans. A paz pelo direito. Tradução Lenita Ananias do Nascimento. São Paulo: WMF Martins Fontes, 2011.

LAFER, Celso. Comércio, desarmamento e direitos humanos: reflexões sobre uma experiência diplomática. São Paulo: Paz e Terra, 2006. 


\section{Democracia}

LASMAR, Jorge Mascarenhas; CASARÕES, Guilherme Stolle Paixão e. A Organização das Nações Unidas. Belo Horizonte: Del Rey, 2006.

MCGREAL, Chris. 70 years and half a trillion dollars later: what has the UN achieved? The Guardian. England: London, 7 set. 2015. Disponível em: https://www.theguardian.com/world/2015/sep/07/what-has-the-un-achieved-united-nations. Acesso em: 31 maio 2017

NAÇÕES UNIDAS DO BRASIL - ONU. Países-membros da ONU, 2017. Disponível em: https://nacoesunidas.org/ conheca/paises-membros/. Acesso em: 29 ago. 2017.

ROSA, Renata de Melo. A ONU, setenta anos depois, para que serve? In: JUBILUT, Liliana Lyra; SILVA, João Carlos Jarochinski; RAMINA, Larissa. A ONU aos setenta: contribuições, desafios e perspectivas. Boa Vista: EDUFRR, 2016. p. 87-110.

SANTOS, Milton. Técnica, espaço e tempo: globalização e meio técnico-científico. São Paulo: Hucitec, 1997.

STRANGER, Irineu. Relações Internacionais. São Paulo: LTr, 1998.

TOTA, Pedro. Segunda Guerra Mundial. In: MAGNOLI, Demétrio (org.). História das guerras. p. 355-389. São Paulo: Contexto, 2011.

WIGHT, Martin. A política de poder. Tradução Carlos Duarte. Brasília: UnB, 2002.

ZACHER, Mark W. Os pilares em ruína do templo de Vestfália: implicações para a governança global e a ordem internacional. In: CZEMPIEL, Ernst-Otto; ROSENAU, James N. (org.). Governança sem governo: ordem e transformação na política mundial. Tradução Sérgio Bath. Brasília: UnB, 2000. 